\title{
A Factual Research on Employee Green Behavior in Select Medical Research Centres - Medical Tourist Staffs' Perspective
}

\author{
K S Usman Mohideen, V Selvakumar, H Hari Harasudha, K Maran
}

\begin{abstract}
Employee Green Behavior (EGB) is the positive environmental behavior that the employees exhibit in an organization. It is one of the several methods in which environment could be protected. The purpose of this study was to gain an understanding of variables that impact EGB of employees in the select medical centers. This descriptive paper on EGB gives insight into the significance of employee green behavior which plays a significant role in protecting the environment and analyses the benefits of green behavior for the employees as well as the environment. The study explored various variables such as Sustaining work, Avoiding harm, Conserving resources and Taking initiatives from medical tourist staffs perspective. The sample size selected for the study is 150 respondents. The respondents are selected by simple random sampling method and structured questionnaire is used to collect data. Correlation, Independent sample t-test and Chi-square were used to analyze the data. There is a significant difference between Marital Status and Avoiding Harm and Marital status and Conserving Resources whereas there is no significant difference between Marital Status and Sustaining Work and Marital Status and Taking Initiative. Positive relationship exhibited between considered variables.
\end{abstract}

Keywords: Avoiding Harm, Conserving Resources, Employee Green Behavior, Medical Research Centers and Medical Tourist Staffs, Sustaining Work and Taking Initiatives.

\section{INTRODUCTION}

Environmental sustainability is a critical dimension of corporate well-being in modern era. It can be enhanced by adopting Employee Green Behavior (EGB) Practices. Dilcher defines EGB "as any measurable individual behavior that contributes to or detracts from environmental sustainability goals in the work context." The author states that EGB is an essential component of organizational environmental sustainability. Gonzalez-Benito opined that there is a crucial need for an enthusiastic approach towards

Revised Version Manuscript Received on 10, September 2019.

Dr. K S Usman Mohideen, Assistant Professor, Department of Management Studies, Sri Sai Ram Engineering College, Sai Leo Nagar, West Tambaram, Chennai, Tamil Nadu, India.(Email: usman1113@gmail.com)

Mr. V Selvakumar, Head of the Department, Department of Management Studies, Sri Sai Ram Institute of Technology, Sai Leo Nagar, West Tambaram, Chennai, Tamil Nadu, India.(Email: hod.mba@sairamit.edu.in)

Ms. H Hari Harasudha, Full Time Research Scholar, School of Management Studies, Tamil Nadu Open University, Saidapet, Chennai, Tamil Nadu, India.(Email: hariharasudha.mba@gmail.com)

Dr. K Maran, Professor \& Director, Sri Sai Ram Institute of Management Studies, Sai Leo Nagar, West Tambaram, Chennai, Tamil Nadu, India.(Email: directorsims@ sairam.edu.in) environmental management across the world. Improved adoption of ecological management is called Green Management Strategy. It aims at protecting and measuring environmental aspects. Observational learning allows people to pick up on effective behaviors and adapt to new and ambiguous environments. There is an accumulating pressure to address the long term consequences of environmental degradation and pollution and to improve the responsiveness. These practices are called as green practices and it should be formally and informally incorporated within the organization. Employee Green Behaviour variables considered are Sustaining work, Avoiding Harm, Conserving Resources and Taking Initiatives. Medical tourists are the people who come from other countries for availing treatment. Medical tourist staffs are the staffs who are assigned for taking care of medical tourist. The positive employee green behavior of medical tourist staffs creates favorable impression among medical tourists and helps to bring more and more medical tourists not only for the economy and cost but also for the care for ecology.

\section{REVIEW OF LITERATURE}

Mandip (2012), in his research on the practice of green HR he stated that green HR should be incorporated in each and every process of HR starting from recruitment, training, appraisal, employee relation and reward. Green initiatives within HRM is major part of CSR. Green HR involves two essential elements: environmentally-friendly HR practices and the preservation of knowledge capital.

Lather (2015), author states that employees perceive that top management is committed to environmental management, employees are provided with environmental training before their joining or during their job as and when required and companies implement green programs which have an impact on environmental performance.

Piotr (2016), the author examines the direct effects of green organizational climate (GOC) on Organizational Citizenship behavior with the mediating effect of individual factors. It is found that employee values and commitment were positively related to OCB of employees who engage in EGB. 


\section{A Factual Research on Employee Green Behavior in Select Medical Research Centres - Medical Tourist Staffs' Perspective}

Nadia (2017), the idea of green working environment as reflected by senior managers' endorsement. Findings indicates that senior managers are not using human resource management practices to encourage EGB.

Jovita (2017), the author identified Employees initiate programs and policies that are environmentally friendly and also give preferences to environmental interests like turning down environmentally unfriendly project. Employees must avoid harm to the environment by planting trees in their workplace, disposing of biodegradable and non-biodegradable waste separately.

Manoharan (2017), findings of study revealed that only the external factors have a significant impact on pro-environmental behavior of employees. The internal factors have a positive effect but not much significant.

Qaisar (2018), the analyzed that there is a positive relationship between EGB and environmental sustainability.

\section{STATEMENT OF PROBLEM}

Environmental sustainability is emerging as a critical facet of corporate existence. The need for the study is to identify if the staff in the organization are engaging themselves in the activities for green environment. There is also a need to identify if the employees are involved in voluntary green behaviour. The operating cost of the organization has been increased by around $13 \%$.There is excessive usage of scan and $\mathrm{x}$-ray machines. There is a need to identify if these machines have any impact on electrical usage in the organization. There is a need to identify the measures taken by the individuals to keep the organization environmental friendly and the need to find out how the individuals motivate their co-workers to adopt green behaviour policies.

\section{OBJECTIVES OF THE STUDY}

$>$ To assess the level of green behaviour among employees.

$>$ To examine the relationship between dimensions of green behaviour.

$>$ To assess the impact of demographic factors on dimensions of employee green behaviour.

$>$ To evaluate the role of dimensions of employee green behaviour.

\section{SCOPE OF THE STUDY}

This paper will help the organization to improve its green behaviour activities. It will also help the organization to train their staff voluntarily involve in these activities in near future. It covers various variables such as Sustaining Work, Avoiding Harm, Conserving Resources and Taking Initiatives. This study also helps the management to understand the commitment of the employees towards organization green behaviour. It covers employees from all levels of the organization.

\section{RESEARCH METHODOLOGY}

Research Design: Descriptive research

Data Collection: The tool for collecting primary data is "Questionnaire." The questionnaire consists of demographic questions and other variables which based on few factors namely, "Sustaining work, Avoiding harm, Conserving

resources and Taking initiatives." Responses were recorded along a five-point Likert scale ranging from 1(Strongly Disagree) to 5 (Strongly Agree). Data collected by circulating the questionnaire through emails of employees from select medical research centers. Secondary data collected from the journals, books, Internet, etc.

Sample Unit: Nursing and House Keeping staffs working in select medical research centers in Tamil Nadu.

Sampling Technique: Simple Random Sampling

Statistical Tools applied: Correlation, Chi-square and Independent Sample T-test.

\section{LIMITATIONS OF THE STUDY}

$>$ Employees were hesitant to give information on medical wastages.

$>$ Some of the employees did not spend much time to provide a complete response to the structured questions.

$>$ The respondents were majorly from the nursing department; hence various other departments couldn't be covered.

\section{RESULTS AND DISCUSSION}

$>38.3 \%$ of the employees are between the age group of 25-30 years.

$>55.6 \%$ of the employees are female.

$>55.6 \%$ of the employees have completed undergraduate.

$>75.9 \%$ of the employees are married.

$>30.1 \%$ of employees have 6-8 years of overall work experience.

$>45.9 \%$ of the employees agree that they call concerned department when there is wastage of resources.

$>42.1 \%$ of the employees agree that they are looking for more environment-friendly programs.

$>40.6 \%$ of employees strongly agree that they utilize environmental-friendly technologies.

$>40.6 \%$ of the employees strongly agree that they use "user manual" for new equipment

$>39.8 \%$ of the employees agreed that they clean their workplace after work.

$>40.6 \%$ of the employees agree that they keep things at its right places only.

$>38.3 \%$ of the employees strongly agree that they advise others in handling the equipment.

$>35.3 \%$ of the employees agree that they would advise others to be environmentally friendly.

$30.1 \%$ of employees agree that they take measures to prevent pollution.

$>47.4 \%$ of employees agree that they dispose of products in the proper way.

$>43.6 \%$ of employees agree that they discuss the cons of the process.

35.3\% of employees strongly agreed that they would welcome change in the process.

$>41.4 \%$ of employees agree that they don't cause damage to the environment through their official decision. 
$36.8 \%$ of employees agreed that they avoid technologies that are harmful to the environment.

$>34.6 \%$ of employees strongly agreed that they reduce water consumption.

$>37.6 \%$ of employees strongly agree that they reduce electrical usage when not needed.

$>33.1 \%$ of employees strongly agree that they would save resources for future use.

$31.6 \%$ of them agreed that they prefer recycling process in the workplace.

$>34.6 \%$ of the employees agree that they would take up new means to use fewer resources.

$30.1 \%$ of the employees agree that they reduce the font size while printing to save papers.

36.1\% of the employees agree that they use one-sided paper for rough use.

$>30.8 \%$ of the employees agree that they turn off the monitor when not in use.

$>28.6 \%$ of the employees agree that they avoid printing official documents when not utmost needed.

$>28.6 \%$ of employees agree that they avoid $\mathrm{A} / \mathrm{C}$ when not required.

$>32.3 \%$ of employees agree that they use their cups instead of disposable ones.

$>30.8 \%$ of employees agree that they use stairs instead of lift in their organization

$>36.1 \%$ of employees agreed that they avoid light during day time.

$>30.1 \%$ of employees agree that they use only single/ disposable products.

$>31.6 \%$ employees agree that they want to implement environmental-friendly programs with their colleagues.

$>31.6$ of the employees agree that they take steps to maximize the life span of their office equipment.

$>26.3 \%$ of the employees strongly agree that they avoid inefficient work process to save natural resources.

$>28.3 \%$ of the employees agree that they avoid office equipment for their own usage.

$>27.3 \%$ of the employees agree that they want to implement new policy to be environmentally friendly.

$>24.1 \%$ of employees agree that they want to promote earth day activities.

\section{CORRELATION}

Ha0: There is no significant relationship between Sustaining Work and Avoiding Harm.

Hb0: There is no significant relationship between Sustaining Work and Conserving Resources.

Hc0: There is no significant relationship between Sustaining Work and Taking Initiatives.

Hd0: There is no significant relationship between Avoiding Harm and Conserving Resources.

He0: There is no significant relationship between Avoiding Harm and Taking Initiatives.

Hf0: There is no significant relationship between Conserving Resources and Taking Initiatives.
Table 01: Pearson Correlation among considered variables

\begin{tabular}{|l|l|l|l|l|}
\hline & $\begin{array}{l}\text { Sustaining } \\
\text { Work }\end{array}$ & $\begin{array}{l}\text { Avoiding } \\
\text { Harm }\end{array}$ & $\begin{array}{l}\text { Conserving } \\
\text { Resources }\end{array}$ & $\begin{array}{l}\text { Taking } \\
\text { Initiatives }\end{array}$ \\
\hline $\begin{array}{l}\text { Sustaining } \\
\text { Work }\end{array}$ & 1.000 & 0.669 & 0.625 & 0.564 \\
\hline $\begin{array}{l}\text { Avoiding } \\
\text { Harm }\end{array}$ & & 1.000 & 0.694 & 0.621 \\
\cline { 1 - 1 } $\begin{array}{l}\text { Conserving } \\
\text { Resources }\end{array}$ & & & 1.000 & 0.619 \\
\cline { 1 - 1 } $\begin{array}{l}\text { Taking } \\
\text { Initiatives }\end{array}$ & & & & 1.000 \\
\hline
\end{tabular}

*Sig. Value 0.000

From the table it is inferred that the considered variables have a positive correlation between themselves. $\mathrm{H} 0$ is rejected and $\mathrm{H} 1$ is accepted. Thus $\mathrm{Ha} 1, \mathrm{Hb} 1, \mathrm{Hc} 1, \mathrm{Hd} 1, \mathrm{He} 1$, Hf1 are accepted. Therefore there is a significant relationship between considered variables among themselves.

\section{CHI SQUARE}

To test the association between looking for environmental friendly program and appreciate others to be environmentally friendly.

Hg0: There is no association between looking for environmental friendly program and appreciate others to be environmentally friendly.

Hg1: There is an association between looking for environmental friendly program and appreciate others to be environmentally friendly.

Table 02: Testing association between looking for environmental friendly program and appreciate others to be environmentally friendly

\begin{tabular}{|c|c|c|}
\hline & $\begin{array}{l}\text { Looking for an } \\
\text { environmental-friendly } \\
\text { program }\end{array}$ & $\begin{array}{l}\text { Appreciate } \\
\text { others to be } \\
\text { environmentally } \\
\text { friendly }\end{array}$ \\
\hline $\begin{array}{c}\text { Chi-Squ } \\
\text { are }\end{array}$ & 79.744 & 51.549 \\
\hline Df & 4 & 4 \\
\hline $\begin{array}{c}\text { Asymp. } \\
\text { Sig. }\end{array}$ & 0.000 & 0.000 \\
\hline
\end{tabular}

\section{Interpretation}

Since table value is less than significant value. H0 is rejected and $\mathrm{H} 1$ is accepted. Therefore there is an association between looking for environmental friendly program and appreciate others to be environmentally friendly.

\section{INDEPENDENT SAMPLE T - TEST}

To test the significant difference between Marital Status and Sustaining Work, Avoiding Harm, Conserving and Taking Initiatives.

Hh0: There is no significant difference between Marital Status and Sustaining Work.

Hi0: There is no significant difference between Marital Status and Avoiding Harm. 
Hj0: There is no significant difference between Marital Status and Conserving.

Hk0: There is no significant difference between Marital Status and Taking Initiatives.

Table 03: Testing significance difference between Marital Status and Avoiding Harm

\begin{tabular}{|l|l|l|l|}
\hline & F & Sig. & Equality of variance \\
\hline $\begin{array}{l}\text { Sustaining } \\
\text { Work }\end{array}$ & 0.322 & 0.057 & 0.395 \\
\hline $\begin{array}{l}\text { Avoiding } \\
\text { harm }\end{array}$ & 1.955 & 0.016 & 1.939 \\
\hline Conserving & 0.832 & 0.036 & 0.335 \\
\hline $\begin{array}{l}\text { Taking } \\
\text { Initiatives }\end{array}$ & 0.117 & 0.074 & 1.140 \\
\hline
\end{tabular}

\section{Interpretation}

Since the table value is less than significant value, $\mathrm{HiO}$ and $\mathrm{HjO}$ are rejected and $\mathrm{Hil}$ and $\mathrm{Hj} 1$ are accepted. Therefore, there is a significant difference between Marital Status and Avoiding Harm and Marital status and Conserving.

Since the table value is more than significant value, Hh0 and $\mathrm{Hk} 0$ are accepted and $\mathrm{Hh} 1$ and $\mathrm{Hk} 1$ are rejected. Therefore there is no significant difference between Marital Status and Sustaining Work and Marital Status and Taking Initiatives.

\section{SUGGESTIONS}

$>$ The organization should try to reduce the usage of paper by keeping medical records and other files in database.

$>$ The organization should recognize and appreciate the employees with certificates or rewards to who are involved in voluntary green behaviour.

$>$ The organization should create more awareness about scarce of water resource to housekeeping staffs and use modular taps to save water.

$>$ The HR department should conduct various programs such as an awareness program and training program to educate them about energy savings.

$>$ The organization should create awareness on recycling by organizing a clean-up day within and outside the organization.

$>$ The organization should use recycled paper or keep tracker in a computer to avoid excessive usage of paper.

$>$ The hospital should use a joint database or information management system to avoid printing of documents.

$>$ The hospital should ask employees to use their cups or stop providing disposable cups to its employees.

$>$ The hospital should have place notice on lifts indicating that the elevators are only for the usage of patients and for emergency purpose only.

$>$ The organization should encourage and appreciate staff who try to implement environmental-friendly programs with others.

$>$ The organization should conduct training program at periodical interval to educate them about inefficient work process.

$>$ The organization should conduct cleaning and tree-planting programs to involve employees in promoting earth day activities.

\section{CONCLUSION}

EGB is an essential component of organizational environmental sustainability. There was a need for the study to identify if the staff in the hospital are engaging themselves in the activities for green environment. There is also a need to determine if the employees are involved in voluntary green behavior. The study shows that the employees in select institute and medical center are aware of employee green behavior. It is also analyzed that there is number of employees willing to implement environmental-friendly programs and are ready to appreciate others who are involving in such programs. Involvement in the environmental-friendly program shows that the employees want to participate themselves in improving and in keeping the environment green. The author founds that there is a significant difference between the various variables used and their marital status. It can be suggested that the organization should try to reduce the usage of paper by keeping medical records and other files in database. The organization should conduct cleaning and tree-planting programs to involve employees in promoting earth day activities. There is also positive relationship between sustaining work, avoiding harm, conserving resources and taking initiatives.

\section{REFERENCES}

1 Andrea Kim (2014), Multilevel Influences on Voluntary Workplace Green Behaviour: Individual Differences, Leader Behaviour and Co-worker Advocacy, Vol.43 Issue-5, PP. 1335-1358.

2 Felipe (2012). Do I Look Good In Green? A Conceptual Framework, Amazon, organizations and sustainability, Vol.6 Issue- 2, PP. 7-23.

3 Gill Mandip (2012), Green HRM: People Management Commitment to Environmental Sustainability, Research Journal of Recent Sciences, Vol.1 Issue- 6, PP. 244-252.

4 Jacqueline Christine (2014), Development of an Employee Green Behavior Descriptive Norms Scale, Electronic Theses, Projects, and Dissertations, Vol.1 Issue-2, PP. 83

5 Jovita Sherin (2017). Is it time to promote employee green behavior? The need and scope, Journal of Management Research and Analysis, Vol.3 Issue- 4, PP. 117-122.

6 Lather (2015), Impact Of Green Human Resource Factors On Environmental Performance In Manufacturing Companies: An Empirical Evidence, international journal of engineering and management science, Vol.6 Issue- 1, PP. 23-30.

7 Lindsay J. McCunn (2012), Do green offices affect employee engagement and environmental attitudes? Architectural Science Review, Vol.2 Issue- 8, PP. 128 134.

8 Manika, D. Wells (2015), The Impact of Individual Attitudinal and Organisational Variables on Workplace Environmentally Friendly Behaviors, Journal of Business Ethics, Vol.3 Issue-5, PP. 663- 684.

9 Manoharan (2017), The Pro-Environmental Behavior of Employee in an Apparel Manufacturing Organization in Nuwara-Eliya District of Sri Lanka, Sri Lankan Journal of Human Resource Management, Vol.1 Issue- 4, P.26.

10 Nadia (2017), Green Workplace Behavior in Saudi Arabia: The Case of Enviro Co, Journal of Management and Sustainability, Vol.7 Issue- 1, PP.23-27.

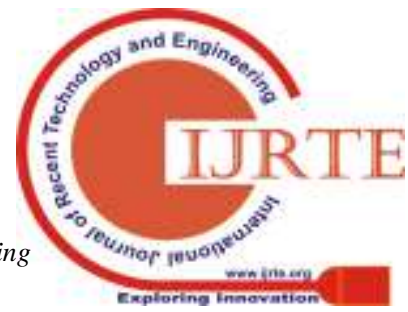


11 Piotr (2016), Green organizational climates and employee pro-environmental behavior in the hotel industry, Journal of Sustainable Tourism, Vol.26 Issue- 7, PP. 1142-1159.

12 Qaisar Iqbal (2018), Employee's green behavior for environmental sustainability: a case of the banking sector in Pakistan, World Journal of Science, Technology and Sustainable Development, Vol.15 Issue- 2, PP.118-130.

13 Rachel (2015), Employee Motives for Engaging in Environmentally Sustainable Behaviors: A Multi-Study Analysis, Digital conservancy, Vol.1 Issue-9, P. 23.

14 Ranitha (2017), Employee Green Behavior: A Case in Manufacturing \& Service Sector in Sri Lanka, International Journal of Academic Research in Business and Social Sciences, Vol.7 Issue-8, P. 12.

15 Thanita (2017), The model of corporate social responsibility, organizational commitment and employee green behavior, UTCC International Journal of Business and Economics, Vol.9 Issue-2, P. 23.

16 Thomas A. Norton (2015) Employee Green Behavior: A Theoretical Framework, Multilevel Review, and Future Research Agenda, Organization \& Environment, Vol.28 Issue- 1, PP. 103 - 125.

17 Vincent (2014), Encouraging sustainability in the workplace: A survey on the pro-environmental behavior of university employees, Journal of Cleaner Production, Vol.7 Issue-3, P. 18. 